\title{
The burden of deliberate self-harm on the critical care unit of a peri-urban referral hospital in the Eastern Cape: A 5-year review of 419 patients
}

\author{
D M Favara \\ East London Hospital Complex, Eastern Cape \\ D M Favara, MB ChB, community service medical officer
}

Corresponding author: D M Favara (dmf@dmf.co.za)

\begin{abstract}
Background. Buffalo City Municipality (BCM) in the Eastern Cape (EC) has the highest susceptibility to deliberate self-harm (DSH) of any South African city. The EC also has a shortage of critical care beds.

Objective. This study reviewed DSH admissions over 5 years to the critical care unit (CCU) of Cecilia Makiwane Hospital (CMH), a large peri-urban hospital in the EC. It also examined the financial burden that DSH exerts on public-sector critical care.

Methods. DSH cases admitted to CMH's CCU between January 2006 and December 2010 were retrospectively reviewed. Patients under 13 years of age were excluded. Age, gender, admission duration, agent used, outcome and toxicology results were recorded. Cost was estimated using the Department of Health 2012 fee schedule.

Results. A total of 419 patients, comprising $17 \%$ of total CCU admissions, were included in the study. Cholinesterase inhibitors (CIs) were the most common agents ingested (55\%). Compared with non-CI groups, CI patients where admitted for twice as long from admission to discharge $(p<0.0001)$, but had a lower mortality rate $(p=0.0344)$. No significant difference was found between gender and survival $(p=0.5725)$ and between the yearly DSH CCU admission means $(p=0.052)$. CI cases cost a minimum of R15 966.29 per admission and DSH CCU cases cost over R1 million per annum.

Conclusion. DSH imposes an appreciable burden on the CCU services in the EC. There is a need to better control the unregulated availability of CIs (and related public education) as well as to improve psychiatric and psychological services in the EC rural areas.

S Afr Med J 2013;103(1):40-43. DOI:10.7196/SAMJ.6231
\end{abstract}

According to the World Health Organization, nearly 1 million people die by suicide annually, ranking it amongst the top 20 causes of death for all ages globally. ${ }^{1}$ By 2020, it is estimated that suicide will contribute more than $2 \%$ of the global burden of disease. ${ }^{2}$ In South Africa, longterm data for completed suicide, attempted suicide and parasuicide (collectively referred to as deliberate self-harm (DSH)) are limited. ${ }^{3-6}$ Reasons for this include poor statistical record keeping on injury and death during the apartheid years, especially for the black population; changes to the Birth and Death Registrations Act of 1992 which allow the omission of the specific manner of death from death certificate records; and until recently, a lack of systematic national data collection. ${ }^{3}$

SA has limited critical care resources. ${ }^{7}$ The 2007 National Audit of Critical Care indicated that SA's public sector contains only $36 \%$ (1 783 of 4 168) of the country's high care unit (HCU) and intensive care unit (ICU) beds. ${ }^{7}$ There is also a maldistribution of these resources, with $86 \%$ of all $\mathrm{HCU}$ and ICU beds found in the Western Cape, Gauteng and KZN. ${ }^{7}$ The Eastern Cape (EC), one of the poorest provinces in the country, has a critical care bed-to-population ratio of 1:37 000, compared with 1:14 000 in the Western Cape. ${ }^{?}$

Within the EC, Buffalo City Municipality (BCM) consists of the towns of East London, King William's Town and Bhisho. Of its population of some 700000 people, $64 \%$ earn less than the household subsistence level of R1 500 per month and $41 \%$ are under 20 years of age. ${ }^{8}$ Individuals living in BCM have SA's highest probability of committing suicide. ${ }^{3}$

This audit involves all cases of DSH admitted to the critical care facilities of Cecilia Makiwane Hospital (CMH) in BCM over a 5 -year period. $\mathrm{CMH}$ is a large peri-urban hospital that, with its sister institution Frere Hospital, serves a third of the EC's population of 6 million inhabitants. CMH's critical care unit (CCU) combines 6 IC beds and $6 \mathrm{HC}$ beds in one unit. This is the first SA study exploring the financial burden that DSH cases exert on a limited public-sector critical care service.

\section{Methods}

The study was a retrospective review of the 5-year period from 1 January 2006 to 31 December 2010. Approval was obtained from the institutional ethics review body. Patients were recruited to the study if they were admitted to the CCU following DSH and were 13 years of age or older. All admission data were extracted from the CCU admission and discharge files. Age, gender, duration of stay, aetiology, mortality and site of residence were recorded.

The patients' toxicology investigations were reviewed using the local National Health Laboratory Service database. Admission costs were calculated using the facility fees listed in the current costing tables of the SA Department of Health. ${ }^{9}$

\section{Results}

During the study period 419 DSH cases where admitted to CMH's critical care facility. Table 1 lists their characteristics.

Cholinesterase inhibitor (CI) toxicity led to $55 \%$ of all admissions. Patients poisoned with CIs were unlikely to have taken other agents as well. The second most common group had ingested agents not identified by history, examination or standard laboratory testing.

Table 2 lists the top 5 agents used by admitted DSH patients. CI toxicity was caused by patients ingesting organophosphates 


\section{RESEARCH}

Table 1. Characteristics of DSH patients admitted to critical care

\begin{tabular}{lcccc}
\hline & $\begin{array}{c}\text { Total case number } \\
(\boldsymbol{N})\end{array}$ & $\begin{array}{c}\text { Mean age } \\
(\text { years })\end{array}$ & $\begin{array}{c}\text { Mean admission duration } \\
(\mathbf{h})\end{array}$ & $\begin{array}{c}\text { Mortality } \\
(\%)\end{array}$ \\
\hline Male & 196 & $31.31(95 \% \mathrm{CI} \pm 1.9)$ & $85.62(95 \% \mathrm{CI} \pm 12.96)$ & 8.67 \\
Female & 223 & $27.91(95 \% \mathrm{CI} \pm 1.18)$ & $73.78(95 \% \mathrm{CI} \pm 606.86)$ & 6.76 \\
Total & 419 & $29.50(95 \% \mathrm{CI} \pm 1.3)$ & $79.32(95 \% \mathrm{CI} \pm 8.9)$ & 7.64
\end{tabular}

Table 2. The top 5 DSH agents necessitating admission to critical care

\begin{tabular}{lccccc}
\hline Agent & Frequency & $\begin{array}{c}\text { Overlap with other } \\
\text { aetiologies }(\%)\end{array}$ & $\begin{array}{c}\text { Mean age } \\
\text { (years) }\end{array}$ & $\begin{array}{c}\text { Mean admission duration } \\
(\mathbf{h})\end{array}$ & $\begin{array}{c}\text { Mortality } \\
(\%)\end{array}$ \\
\hline Cholinesterase inhibitors & 232 & 2 & $30.4(95 \% \mathrm{CI} \pm 1.9)$ & $102.45(95 \% \mathrm{CI} \pm 12.45)$ & 5.45 \\
Unknown agents & 75 & 4 & $28.9(95 \% \mathrm{CI} \pm 2.8)$ & $54.22(95 \% \mathrm{CI} \pm 15.96)$ & 11.94 \\
Paracetamol & 45 & 40 & $27.3(95 \% \mathrm{CI} \pm 3.9)$ & $50.72(95 \% \mathrm{CI} \pm 24.92)$ & 7.14 \\
Tricyclic antidepressants & 35 & 57 & $30.1(95 \% \mathrm{CI} \pm 4.6)$ & $43.51(95 \% \mathrm{CI} \pm 12.20)$ & 6.06 \\
Corrosive substances & 15 & 20 & $28.1(95 \% \mathrm{CI} \pm 4.7)$ & $60.48(95 \% \mathrm{CI} \pm 22.95)$
\end{tabular}

or carbamates. These agents are commonly used as regulated agricultural insecticides, and cause cholinergic excess by inhibiting cholinesterase function. As direct assay of these two agents is not available at $\mathrm{CMH}$, a surrogate marker (decreased serum cholinesterase levels) was used to verify clinical diagnosis. All patients with CI intoxication received aggressive standardised atropinisation therapy.

The mean admission duration was 79.32 hours $(95 \%$ CI \pm 8.9 hours). Compared with those poisoned with other agents, patients ingesting CIs were admitted in the CCU for more than twice as long (102.45 hours, $95 \% \mathrm{CI} \pm 12.5$ hours $f$, v. 50.63 hours, $95 \% \mathrm{CI}$ \pm 7.8 hours, $p<0.0001$ ). Only one trauma-related DSH case, a survivor of a self-inflicted hanging, was admitted to the CCU during the 5 -year review period.

The overall percentage mortality was $7.64 \%$. Mortality was significantly lower in the CI group compared with the other groups $(5.20 \%$ v. $10.70 \%, p=0.0344)$ There were no statistically significant differences in survival between men and women $(p=0.5725)$.

The annual burden of DSH cases per year at the CCU is shown in Fig. 1. DSH admissions to critical care peaked in summer and dipped during winter (Fig. 2). Although admissions appear to be decreasing, since a peak incidence in 2006 (Table 3), analysis of variance

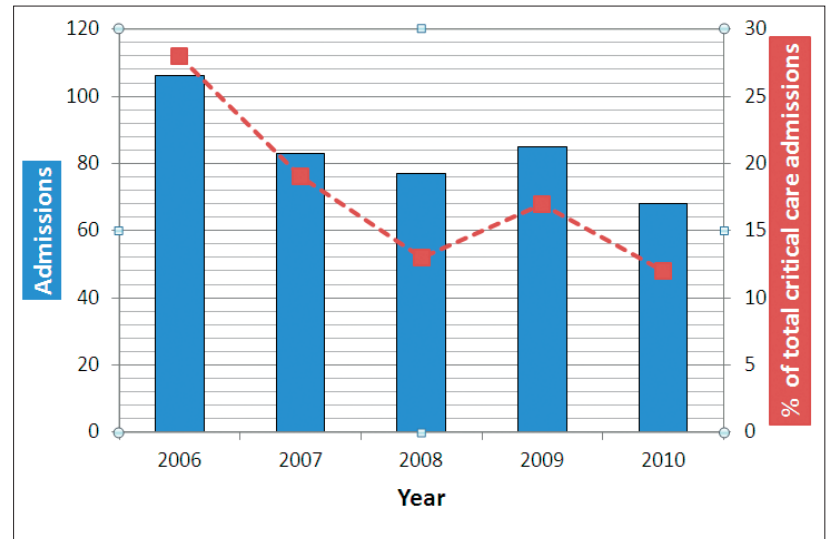

Fig. 1. Yearly DSH critical care admissions.
(ANOVA) testing revealed no statistically significant difference in the yearly means $(p=0.052)$.

Facility costs for DSH admissions to critical care are presented in Table 3. Because the CCU at $\mathrm{CMH}$ combines its intensive care and high care units, it proved impossible to retrospectively determine when patients were moved from the ICU to the HCU facility, or vice versa. Therefore an averaged costing model was created to achieve a minimum average cost for each critical care admission. The daily rate of R4 831 was calculated by averaging the ICU (R6 634/day) and HCU (R3 028/day) facility costs. On the basis of clinical observation, most $\mathrm{CI}$ admissions spent the majority of their critical care time in the ICU and not in the lower-cost HCU.

\section{Discussion}

In 2008, DSH in SA accounted for $10 \%$ of non-natural deaths, of which the majority of patients were under 29 years of age. ${ }^{10}$

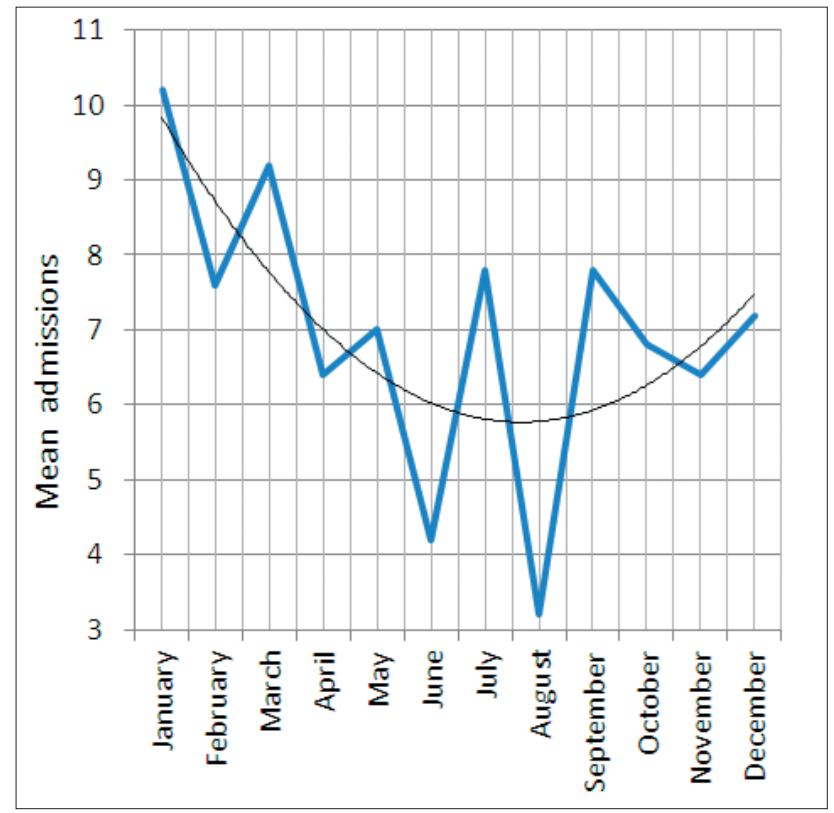

Fig. 2. Seasonal trend of deliberate self-harm cases admitted to critical care. 
Table 3. Facility costs for DSH admissions to critical care

\begin{tabular}{lccc}
\hline & Total case number, $\boldsymbol{N}$ & Cumulative cost for all cases & Average cost per admission \\
\hline Cost complete dataset & 419 & R6 689878.22 & R15 966.29 \\
Cholinesterase inhibitors & 232 & R4 784 236.59 & R20621.71 \\
Non-cholinesterase inhibitors & 187 & R1 905641.63 & R10 190.59
\end{tabular}

Nationally, fatal DSH rates for males and females are estimated to be 25.3/100 000 and 5.6/100 000 respectively. ${ }^{11}$ Non-fatal DSH is estimated to outnumber fatal DSH by up to $20: 1 .^{4}$

$\mathrm{BCM}$ 's residents have the highest probability of fatal DSH compared with other SA cities. ${ }^{3}$ Reasons for the high, and growing, number of cases are thought to include widespread unemployment coupled with minimal economic growth over the last decade; poor availability of healthcare and scarce psychiatric services in rural areas; and the heavy burden of HIV.,12

This study reveals that CI toxicity accounts for over half of all DSH admissions to critical care and that these patients remain in the CCU for twice as long as non-CI DSH admissions. This has significant cost implications, especially for a health service struggling with a large burden of infectious disease and trauma.

It is notable that only one trauma-related DSH case was admitted to the CCU during the 5-year review period. Reasons for this scarcity include the typically fatal nature of such cases, as well as the possibility that such cases are admitted to the CCU but are erroneously documented as standard trauma cases.

Although not statistically significant, this study found that the number of DSH admissions to critical care had been slowly decreasing since a peak incidence in 2006 (Fig. 1). Possible reasons include doctors being more judicious about admitting patients to the overburdened CCU; patients not presenting to hospital; and delays in patients procuring transport to hospital, resulting in their either presenting to casualty dead on arrival or dying soon after arrival (the mean duration of transport from hospital to hospital in the Eastern Cape is 6.5 hours - the longest in the country!). ${ }^{13}$ There is also anecdotal evidence of a small beneficial effect following intervention by local social workers, which aimed to educate the community at large about the dangers of DSH.

DSH admissions to critical care peaked in the summer months and dipped during the winter months (Fig. 2), a trend that is mirrored worldwide. ${ }^{14}$

National facility costs retrieved from the Department of Health were used to calculate the financial implications of the DSH burden on critical care. ${ }^{9}$ The results are likely to be extremely conservative for several reasons. Firstly, difficulties in obtaining accurate estimates of personnel, equipment, diagnostic and therapeutic costs meant these criteria were excluded from the costing. Secondly, as discussed above, the combination of ICU and HCU beds in the CMH CCU meant that only an average ICU/HCU expenditure could be calculated per patient. As local observation suggests that CI toxicity patients (the majority of DSH CCU admissions) spend the majority of their CCU time within intensive care, the true overall minimum admission costs are likely to be much higher than the averaged ICU/HC figures. DSH critical care cases are likely to cost CMH over R1 million annually and, at $20 \%$ of total CCU admissions, impose a significant bed occupancy pressure.

It will be difficult to contain costs in the treatment of DSH patients. Proposals for reducing hospital admissions for DSH argue that many inpatients labelled 'suicidal' are hospitalised unnecessarily and are in fact low-lethality risk DSH cases. ${ }^{15}$ However, this cannot be applied to critically ill DSH patients.
A more effective model for decreasing DSH activity in the EC would be to address the root causes of the despair these patients feel. These problems are multi-factorial and linked to high unemployment and poverty. In the EC, psychological and psychiatric services are mostly clustered around the 3 major cities of Port Elizabeth, East London and Mthatha. Given the poorly functioning referral system, and a primary clinic environment burdened with infectious diseases, patients with psychological or psychiatric problems and vulnerability to DSH risk being turned away, inadequately managed, or lost in the system.

Additionally, there is need for investigation into the production and distribution of organophosphate and carbamate agents, typically sold by street vendors as unregulated combination 'cockroach, rat and insect killer' powders in unmarked bags. DSH patients usually ingest these after mixing them with water. As this study was retrospective, it was not possible to determine whether poisoning in some patients was accidental. In this regard, there are anecdotal reports of criminal use of organophosphates and carbamates to poison meat, which is then used to kill watchdogs during robberies, ${ }^{16,17}$ and of unscrupulous home brewers allegedly adding them to traditional beer (umqombothi) to add 'punch'.

\section{Limitations}

This study is limited by its retrospective nature. During data collection it was found that 4 weeks of information was missing from the critical care admission and discharge files (15 March 2006 - 31 March 2006 and 5 April 2008 - 31 April 2008) as pages had been torn out.

In addition, it was found that the time of discharge from critical care was not stated for 129 patients. In these cases it was decided to allocate a set discharge time of midday, which corresponds to the time after the medical rounds and is the usual time that patients are discharged from CMH's CCU.

\section{Conclusion}

DSH imposes an appreciable burden on the Eastern Cape's limited critical care service. As the majority of admissions are due to CI toxicity, there is urgent need for the control of unregulated organophosphate and carbamate distribution, as well as for public health education on the dangers of ingesting these substances. Lastly, there is need for improved psychiatric and psychological services in the rural areas of the Eastern Cape.

Acknowledgements. DMF thanks Professor A Parrish (Department of Internal Medicine, ELHC); Professor A Leiman (Department of Economics, UCT); Dr H Uys (Department of Psychiatry, ELHC); Mr A Hawkes (NHLS Lab, CMH); and CMH critical care nursing staff.

\section{References}

1. World Health Organization. Suicide Prevention and special programmes. Geneva: World Health Organization, 2012. http://www.who.int/mental_health/prevention/suicide/suicideprevent/en/ (accessed 7 June 2012).

2. World Health Organization. Public health action for the prevention of suicide. Geneva: World Health
Organization, 2012. http://www.who.int/mental_health/publications/prevention_suicide_2012/en/ Organization, 2012. http://www.
index.html (accessed August 2012)

3. Burrows S, Vaez M, Laflamme L. Sex-specific suicide mortality in the South African urban context: the

3. Burrows S, Vaez M, Laflamme L. Sex-specific suicide mortality in the South African urban context: the role of age, race, and geographical location. Scand J Public Health 2007;35(2):133-139. [http://dx.doi.
org/10.1080/14034940600975773] 
4. Joe S, Stein DJ, Seedat S, Herman A, Williams DR. Non-fatal suicidal behavior among South Africans: results from the South Africa Stress and Health Study. Soc Psychiatry Psychiatr Epidemio 2008,43(6).454

Joe S, Sten DJ, Seeda S, Hernan A, Whllams DR. Prevalence and correlates of non-fatal suicida

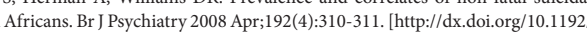
bjp.bp.107.037697

6. Flisher AJ, Liang H, Laubscher R, Lombard CF. Suicide trends in South Africa, 1968-90. Scand J Public Health 2004;32(6):411-418

Bhagwanjee S, Scribante J. National audit of critical care resources in South Africa: unit and bed distribution. S Afr Med J 2007;97:1311-131

8. Buffalo City Municipality Annual Report 2010-2011. Part 1: Overview of the Municipality. http://www buffalocity.gov.za/municipality/annual_report10-11/final/prt1_overview.pdf (accessed 7 June 2011).

9. South African National Department of Health. Uniform patient fee schedule 2012.. http://www.doh. gov.za/docs/programmes/2012/appendixlA.pdf (accessed 7 June 2012)

. The National Injury Mortality Surveillance System (NIMSS). NIMSS Annual Reports: A profile of fatal injuries in South Africa 2008 - 10th Annual Report of the National Injury Mortality Surveillance System. http://www.mrc.ac.za/crime/nimss2008.pdf (accessed 5 June 2011)
1. Burrows S, Laflamme L. Suicide mortality in South Africa: a city-level comparison across sociodemographic groups. Soc Psychiatry Psychiatr Epidemiol 2006;41(2):108-114

Mechan SA, Broom $\mathrm{Y}$. Analysis of a Psy hicide Life Threat Behav 2007;37(1):66-78. [http://dx.doi.org/10.1521/suli.2007.37.1.66]

3. Scribante J, Bhagwanjee S. National audit of critical care resources in South Africa - transfer of critically ill patients. S Afr Med J 2007;97(12 Pt 3):1323-1326.

14. Flisher AJ, Parry CD, Bradshaw D, Juritz JM. Seasonal variation of suicide in South Africa. Psychiatry Res 1997 Jan 15;66(1):13-22.

5. Rissmiller DJ, Steer R, Ranieri WF, Rissmiller F, Hogate P. Factors complicating cost containment in the treatment of suicidal patients. Hosp Community Psychiatry 1994;45(8):782-78

6. Webb D. Temik: Killer on the loose. Health24, 15 June 2010. http://www.health24 com/medical/ Focus_centres/777-2268-2552-2590,31989.asp (accessed 7 June 2012)

17. Arnot LF, Veale DJ, Steyl JC, Myburgh JG. Treatment rationale for dogs poisoned with aldicarb (carbamate pesticide). J S Afr Vet Assoc 2011;82(4):232-238.

\title{
Comparison of HTLV-associated myelopathy (HAM) in HIV-positive and HIV-negative patients at a tertiary South African hospital
}

\author{
C-M Schutte, T Townsend, R Van Coller, S Olorunju \\ Department of Neurology, Steve Biko Academic Hospital, Pretoria \\ C-M Schutte, M Med (Neurol), MD \\ T Townsend, M Med (Neurol),FCN \\ R Van Coller, M Med (Neurol) \\ Medical Research Council, Pretoria \\ S Olorunju, $\mathrm{PhD}$
}

Corresponding author: C-M Schutte (cschutte@meic.up.ac.za)

\begin{abstract}
Background. HTLV-1 associated myelopathy (HAM), or tropical spastic paraparesis, is caused by a retrovirus, the human T-cell lymphotropic virus (HTLV). Although patients with HAM and HIV infection have been described, to our knowledge no direct comparison has been made between patients who are HIV positive and suffering from HAM (HHAM) v. those who are HIV negative and suffering from HAM.

Aim. We aimed to compare clinical and radiological findings in HIV-positive and -negative patients with HAM.

Methods. Adult patients who presented to the Neurology Unit at the Steve Biko Academic Hospital from May 2005 to June 2012 with a progressive myelopathy and HTLV seropositivity were retrospectively identified and their clinical and radiological data were collected and reviewed.

Results. 21 patients with HAM were identified, of whom 9 were HIV-positive and 11 HIV-negative. One patient, whose HIV status had not been established, was not included in the study. Although the trend did not reach statistical significance, co-infected patients tended to present at an earlier age (HHAM 6/9 (66\%) $<40$ years old; HAM 2/11 (18\%) <40 years old) and presented to hospital earlier (HHAM 6/9 $(66 \%)<3$ years symptomatic; HAM $7 / 11(63 \%)>3$ years symptomatic). Cord atrophy occurred in $7 / 8$ dually infected patients and $8 / 10$ HIV-negative patients.

Conclusion. Although the study is limited by the small number of patients, co-infected patients tended to have a younger age of onset and to present to hospital sooner, and thoracic cord atrophy was very common.
\end{abstract}

S Afr Med J 2013;103(1):43-46. DOI:10.7196/SAMJ.5298

Human T-cell lymphotropic virus type-1 (HTLV-1) is a type C retrovirus endemic to tropical areas. Most infected people are asymptomatic carriers, but an estimated $0.25 \%-2 \%$ of carriers develop a progressive myelopathy, known as HTLV-associated myelopathy (HAM) or tropical spastic paraparesis (TSP)., ${ }^{1,2} \mathrm{HTLV}-2$ is more common among intravenous drug abusers, and may present with a clinical picture similar to HAM. ${ }^{2}$

During the last two decades, the HIV pandemic has influenced the spectrum of neurological disorders markedly - up to $40 \%$ of patients with HIV infection clinically show neurological disorders, ${ }^{3}$ and neuropathological abnormalities are even more common. Co-infections of HIV and HTLV-1 have been described ${ }^{4,5}$ and in South Africa a high prevalence of HAM has been found in KwaZulu-Natal, ${ }^{5}$ with up to $36 \%$ of patients showing HIV co-infection. A study from Brazil reported on patients with HIV and $\mathrm{HAM}^{4}$ but did not directly compare patients with and without HIV infection. 


\section{RESEARCH}

We aimed to evaluate the number of patients with HAM seen at the Neurology Department of the Steve Biko Academic Hospital, a tertiary hospital in Gauteng Province, and to compare the clinical and radiological findings of patients who were co-infected with HIV with those who were HIV negative.

\section{Patients and methods}

Patients were identified retrospectively from a list of patients with positive HTLV-1 serology who presented to the National Health Laboratory Services (NHLS) at the Steve Biko Academic Hospital, from May 2005 to June 2012. To ascertain which of these seropositive patients had presented to the hospital's Department of Neurology, the department's electronic database was consulted. Patients included in the study were those 13 years and older, with signs and/or symptoms indicative of possible spinal cord pathology, who had an HIV test done during investigation. Patients excluded were those who had not undergone an HIV test, or who had another recognised aetiology that could better account for symptoms and signs.

The study was approved by the Ethics Committee of the University of Pretoria.

The serology for HTLV-1 detection was performed with ELISA by the NHLS. The spinal cord diameters were measured at level T7 on MRI by a blinded observer who had no access to the patients clinical information. The data was analysed to determine summary statistics and proportions, and the proportions were compared using an independent t-test. Meanwhile, comparison for continuous data was undertaken using $\mathrm{t}$-tests for independent samples. Stata 12 was the software used.

\section{Results}

The records showed 73 patients had positive serology for HTLV-1, of whom 25 were seen at the Department of Neurology with signs of a myelopathy. Of these, 20 were included in the study: 9 tested positive for HIV, and 11 tested negative. Of the 5 patients who were excluded, 4 had alternative aetiologies for their suspected myelopathy: 1 (HIVnegative) was found to have a profound vitamin B12 deficiency, and 3 had spinal tuberculosis. The 5th patient had HAM but had not had not undergone an HIV test.

The clinical data of the patients are presented in Table 1 (HIVnegative patients with HAM) and Table 2 (HIV-positive patients with HAM).

The HIV-negative group consisted of 8 men and 3 women between 21 and 57 years of age, with a mean of $43,7 \pm 8,61$ years. Minimum duration of symptoms was 4 months and maximum 14 years; most patients (7/11) had been symptomatic for 3 years or more. Sphincter disturbances were common, occurring in $8 / 11$ patients $(72 \%)$, and sensory complaints were noted in $9 / 10$. Radiological reports noted atrophy of the cord on MRI in 6 patients, swelling of the cord in

Table 1. Clinical data of HIV-negative patients with HAM

\begin{tabular}{|c|c|c|c|c|c|c|c|}
\hline Number & Sex & $\begin{array}{l}\text { Age } \\
\text { (years) }\end{array}$ & $\begin{array}{l}\text { Duration } \\
\text { (months) }\end{array}$ & $\begin{array}{r}\text { Power } \\
\text { (MRC) }\end{array}$ & $\begin{array}{l}\text { Sphincter } \\
\text { problems }\end{array}$ & $\begin{array}{l}\text { Sensory } \\
\text { symptoms }\end{array}$ & $\begin{array}{l}\text { Cord } \\
(\mathrm{mm})\end{array}$ \\
\hline 1 & $\mathrm{M}$ & 48 & 144 & 2 & $\mathrm{Y}$ & $\mathrm{N}$ & NA \\
\hline 2 & $\mathrm{M}$ & 47 & 48 & 3 & $\mathrm{Y}$ & $\mathrm{Y}$ & 4,4 \\
\hline 3 & $\mathrm{M}$ & 44 & 9 & 3 & $\mathrm{Y}$ & $\mathrm{Y}$ & 9,6 \\
\hline 4 & $\mathrm{M}$ & 43 & 4 & 2 & $\mathrm{~N}$ & NA & 8,8 \\
\hline 5 & $\mathrm{~F}$ & 21 & 12 & 4 & $\mathrm{~N}$ & $\mathrm{Y}$ & 5,1 \\
\hline 6 & $\mathrm{M}$ & 47 & 72 & 4 & $\mathrm{Y}$ & $\mathrm{Y}$ & 4,5 \\
\hline 7 & $\mathrm{~F}$ & 43 & 36 & 3 & $\mathrm{~N}$ & $\mathrm{Y}$ & 3,8 \\
\hline 8 & $\mathrm{M}$ & 51 & 168 & 1 & $\mathrm{Y}$ & $\mathrm{Y}$ & 4,0 \\
\hline 9 & $\mathrm{M}$ & 57 & 36 & 3 & $\mathrm{Y}$ & $\mathrm{Y}$ & 4,2 \\
\hline 10 & $\mathrm{M}$ & 41 & 156 & 4 & $\mathrm{Y}$ & $\mathrm{Y}$ & 5,4 \\
\hline 11 & $\mathrm{~F}$ & 39 & 24 & 3 & $\mathrm{Y}$ & $\mathrm{Y}$ & 4,0 \\
\hline
\end{tabular}

Table 2. Clinical data of HIV-positive patients with HAM

\begin{tabular}{|c|c|c|c|c|c|c|c|c|}
\hline Number & Sex & $\begin{array}{l}\text { Age } \\
\text { (years) }\end{array}$ & $\begin{array}{l}\text { Duration } \\
\text { (months) }\end{array}$ & $\begin{array}{l}\text { Power } \\
\text { (MRC) }\end{array}$ & $\begin{array}{l}\text { Sphincter } \\
\text { problems }\end{array}$ & $\begin{array}{l}\text { Sensory } \\
\text { symptoms }\end{array}$ & $\begin{array}{l}\text { Cord } \\
(\mathbf{m m})\end{array}$ & $\begin{array}{l}\text { CD4 } \\
\times 10^{6} / 1\end{array}$ \\
\hline 1 & $\mathrm{M}$ & 34 & 4 & 3 & $\mathrm{Y}$ & $\mathrm{Y}$ & NA & 5 \\
\hline 2 & M & 42 & 6 & 5 & $\mathrm{Y}$ & $\mathrm{Y}$ & 6,2 & 27 \\
\hline 3 & M & 32 & 5 & 4 & $\mathrm{Y}$ & $\mathrm{N}$ & 6,7 & 31 \\
\hline 4 & $\mathrm{~F}$ & 36 & 96 & 4 & $\mathrm{Y}$ & $\mathrm{N}$ & 4,3 & 300 \\
\hline 5 & $\mathrm{~F}$ & 25 & 11 & 4 & $\mathrm{Y}$ & NA & 4,4 & 484 \\
\hline 6 & M & 36 & 3 & 3 & $\mathrm{Y}$ & $\mathrm{Y}$ & 5,7 & 148 \\
\hline 7 & $\mathrm{~F}$ & 45 & 36 & 4 & $\mathrm{Y}$ & $\mathrm{Y}$ & 4,1 & 1076 \\
\hline 8 & $\mathrm{~F}$ & 31 & 24 & 2 & $\mathrm{Y}$ & $\mathrm{Y}$ & 2,9 & 635 \\
\hline 9 & $\mathrm{~F}$ & 49 & 96 & 2 & $\mathrm{Y}$ & $\mathrm{Y}$ & 5,1 & 580 \\
\hline
\end{tabular}




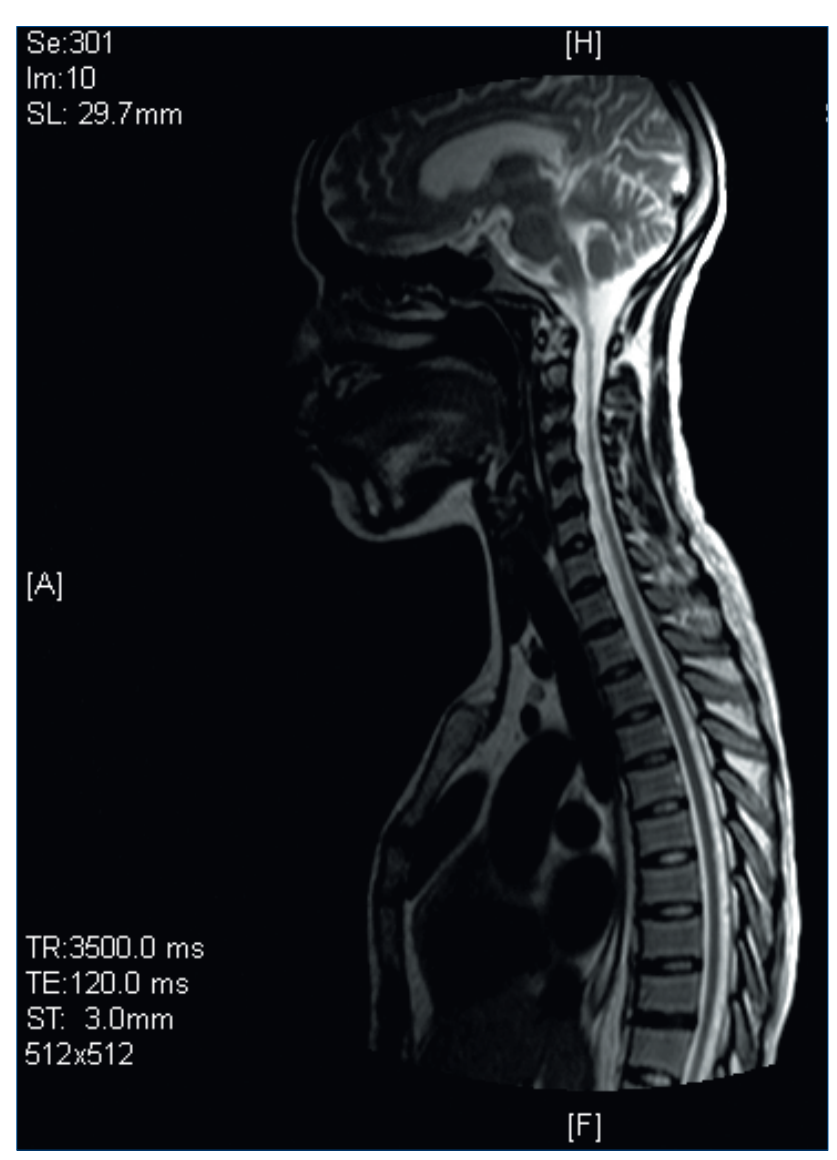

Fig. 1 MRI of patient 5 of the HIV-positive group to illustrate typical thoracic cord atrophy. The cord measured $4,4 \mathrm{~mm}$ at the T7 level.

one and evidence of possible transverse myelitis in one. A blinded observer measured cord diameter at level T7, yielding values ranging from $3.8 \mathrm{~mm}$ to $9.6 \mathrm{~mm}$ (normal: $6.5 \mathrm{~mm}-9.5 \mathrm{~mm}$ ), with a mean of $5.4 \mathrm{~mm}$. Values $<5 \mathrm{~mm}$, implying severe atrophy, were measured in $60 \%$ of patients.

Five females and four males were seen in the HIV-positive group. Their ages ranged from 25 to 49 years with a mean of $36.6 \pm 7.06$ years, but though this was lower than in the HIV-negative group, no evidence of a statistically significant difference with respect to age could be demonstrated. Symptoms had been present for 3 months to 8 years, with $66 \%$ of patients symptomatic for less than 3 years. Sphincter disturbances were present in all patients, and $75 \%$ had sensory complaints. A trend towards statistical significance $(\mathrm{p}<0.055)$ between patients $<40$ years old and $>40$ years old was observed in proportion to sensory symptoms: all older patients had sensory symptoms, compared with half of the younger ones.

Patients' CD 4 counts ranged from 5 to $1076 \times 10^{6} / 1$, while $56 \%$ had counts of less than $350 \times 10^{6} / 1$. Two patients were on highly active antiretroviral therapy (HAART) at presentation. Atrophy of the cord was reported on MRI studies in 4 patients, and a transverse myelitis picture in 1 . When the thoracic cord was measured at level $\mathrm{T} 7$, the values ranged from $2.9 \mathrm{~mm}$ to $6.7 \mathrm{~mm}$ (mean: $4.9 \mathrm{~mm}$ ). Thus, 7/8 patients had cord atrophy, and values of $<5 \mathrm{~mm}$ were seen in $50 \%$ of patients (see Fig 1). There was no evidence of statistical difference in the proportion of patients with cord atrophy in the HIV-positive v. the HIV-negative group.

\section{Discussion}

HTLV-associated myelopathy was first described in the 1950s in the Caribbean, ${ }^{7}$ but it was only in 1985 that the condition was linked with antibodies to the retrovirus known as HTLV. ${ }^{8}$ HAM is a progressive neurodegenerative disease that primarily affects the spinal cord and brain. Risk factors for developing an HTLV-associated myelopathy are the same as those for the transmission of HIV, including younger age of initiation of sexual intercourse and multiple sexual partners. ${ }^{9}$

Patients present with a slowly progressive paraparesis affecting the lower limbs ${ }^{10}$ with a cumulative risk of $1.7 \%$ of developing HAM by the age of 75 years if infected with the virus. ${ }^{11}$ Other clinical features include lumbar pain, detrusor instability, and minor sensory changes, especially paraesthesias and loss of vibration sense..$^{12}$ In our study, the patients singly infected with HTLV showed a disease progression and clinical signs and symptoms in keeping with this classic description.

Our study showed that co-infected patients had a more rapid progression of symptoms that led to an earlier hospital visit. The duration of symptoms in more than half of our patients was less than a year - a finding not documented in other studies. The clinical picture in the dually infected patients may reflect virus-virus interaction. ${ }^{13}$ Dually infected patients have higher levels of HTLV antigen and tax/ rex RNA expression in peripheral blood mononuclear cells, thereby up-regulating HTLV viral message and portending HTLV-associated neurological disease. ${ }^{14}$

Patients in a previous study by Beilke et al. ${ }^{15}$ had high CD 4 counts, ranging from $890-1613 \times 10^{6} / 1$. However, our study shows that HAM can occur at any stage of immune suppression: CD 4 counts ranged from 5 to $1076 \times 10^{6} / 1$, and most of our patients had CD 4 counts of less than $350 \times 10^{6} / 1$. It is unlikely that any of the patients had HIV-associated vacuolar myelopathy since the characteristic lesions (hyperintensities in the posterior and lateral columns) were not noted on MRI. About half of all patients with HAM currently seen at the Steve Biko Academic Hospital are infected with HIV, compared with $33 \%$ in KwaZulu-Natal. ${ }^{5}$ Co-infection of HTLV-1 and HIV in patients with HAM has been mentioned in several studies. ${ }^{4,5,14,15}$ According to Berger et al., ${ }^{16}$ patients co-infected with HIV/HTLV are at increased risk for developing HAM. Elsewhere, a Brazilian study compared the clinical evidence of a myelopathy in 32 co-infected patients (HIV/ HTLV) with 118 patients singly infected with HIV, and found a higher incidence of signs of myelopathy in co-infected patients. ${ }^{4}$

Bhigjee et al. previously found a co-infection rate of HIV and HTLV-1 in $6 \%-8 \%$ of patients with HAM. In a study on the spectrum of myelopathies in HIV positive patients in South Africa, ${ }^{5}$ they found that $33 \%$ of patients had seropositivity for both HIV and HTLV-1, suggesting a higher frequency of myelopathy in co-infected patients. In addition, the patients were younger than those without HIV infection, but otherwise similar, without profound immunosuppression.

Although the findings did not reach statistical significance, the tendency for HIV-positive patients to be symptomatic from HAM at a younger age is also suggested in our study, where 6/9 co-infected patients were younger than 40 years and only $2 / 11$ patients under the age of 40 were singly infected with HTLV. A retrospective study from Louisiana ${ }^{15}$ evaluated HTLV 1 and 2 infection in HIV-positive patients, identifying 5 patients with HAM and HTLV-1 infection whose clinical findings were described, but not specifically compared with those of HIV-negative patients with HAM from the same unit. The patients' ages ranged from 27 - 51 years, with 3 younger than 40 years.

The reported incidence of cord atrophy in HAM varies from $5.6 \%$ to $74 \% .{ }^{17-18}$ Cord swelling may also occur, possibly in the earlier stages of disease. ${ }^{19}$ Measurements of the thoracic cord diameter in our patients showed that $80 \%$ of the HIV-negative group and $88 \%$ from the HIV-positive group showed atrophy of the cord on MRI - more than currently indicated in the literature. In addition to spinal cord abnormalities, white matter 


\section{RESEARCH}

lesions in the brain have also been described in individuals with HAM..$^{20}$ Only 3 of our 9 co-infected patients underwent brain imaging, but cerebral atrophy occurred in all 3, possibly reflecting the longstanding HIV infection. Only 1 showed white matter involvement.

\section{Conclusion}

We found that patients co-infected with HIV and HTLV tended to have a younger age of onset, an earlier presentation to hospital and universal sphincter involvement, and commonly had evidence of spinal cord atrophy. In addition, when compared with other cases with dual infection described in the literature, our patients had a wide range of CD4 counts, indicating that HAM in HIV-positive patients may occur in cases of profound immunosuppression as well as early in the course of infection. The study is limited by the small number of patients assessed, and more data need to be collected to show possible statistical differences.

\section{References}

1. Manns A, Blattner WA. The epidemiology of the human T-cell lymphotrophic virus type I and type II: etiologic role in human disease. Transfusion 1991;31(1):67-75

2. Cabre P, Smadja A, Cabié A, Newton CRJC. Neurological aspects of tropical disease: HTLV-1 and HIV infections of the central nervous system in tropical areas. J Neurol Neurosurg Psychiatry 2000;68:550557. [http://dx.doi.org/10.1136/jnnp.68.5.550]

3. Price RW. Neurological complications of HIV infections. Lancet 1996:348(9025):445-452.

4. Harrison CH, Vaz B, Taveira DM, et al. Myelopathy among Brazilians co-infected with human T-cell lymphotropic virus type I and HIV. Neurology 1997;48(1):13-18.

5. Bhigjee AI, Madurai S, Bill PL, et al. Spectrum of myelopathies in HIV seropositive South African patients. Neurology 2001;57(2):348-351.
6. Medical Research Council. Aids to the Examination of the Peripheral Nervous System. London: Her Majesty's Stationery Office, 1981

Cruickshank EK A neuropathic syndrome of uncertain origin; review of 100 cases. West Indian Med J 1956;5(3):147-158

Gessain A, Barin F, Vernant IC, et al. Antibodies to human T-lymphotropic virus type-I in patients with tropical spastic paraparesis. Lancet 1985;2(8452):407-409.

9. Krämer A, Maloney EM, Morgan OS, et al. Risk factors and cofactors for human T-cell lymphotropic virus type I (HTLV-I)-associated myelopathy/tropical spastic paraparesis (HAM/TSP) in Jamaica. Am J Epidemiol 1995;142(11):1212-121

10. Nakagawa M, Izumo S, Ijichi S, et al. HTLV-1 associated myelopathy: analysis of 213 patients based on clinical features and laboratory findings. J Neurovirol 1995;1:50-61.

11. Maloney EM, Cleghorn FR, Morgan OS, et al. Incidence of HTLV-1-associated myelopathy/tropical spastic paraparesis (HAM/TSP) in Jamaica and Trinidad. J Acquir Immune Defic Syndr Hum Retrovirol 1998;17(2):167-170

12. Castro NM, Rodrigues $\mathrm{W}$ Jr, Freitas DM, et al. Urinary symptoms associated with human T-cell lymphotropic virus type I infection: Evidence of urinary manifestations in large group of HTLV-I carriers. Urology 2007;69(5):813-818.

13. Berger JR, Svenningsson A, Raffanti S, Resnick L. Tropical spastic paraparesis-like illness occurring in a patient dually infected with HIV and HTLV-II. Neurology 1991;41(1):85-87. [http://dx.doi. org/10.1212/WNL.41.1.85

14. Beilke MA, Japa S, Vinson D. HTLV-I and HTLV-II virus expression increase with HIV-1 co-infection Journal Aquir Immune Defic Syndr Hum Retrovirol 1997;17(5):391-397.

15. Beilke MA, Japa S, Moeller-Hadi C, Martin-Schild M. Tropical spastic paraparesis/ Human T leukemi virus type 1-associated myelopathy in HIV type 1 co-infected patients. Clin Infec Dis 2005;41:57-63. [http://dx.doi.org/10.1086/432890]

16. Berger JR, Raffanti S, Svenningsson A, McCarthy M, Snodgrass S, Resnick L. The role of HTLV in HIV 1 neurologic disease. Neurology 1991;41(2 pt 1):197-202.

17. Milagres AC, Jorge ML, Marchiori PE, Segurado AA. Human T-cell lymphotropic virus type 1-associated myelopathy in Sao-Paulo, Brazil. Epidemiologic and clinical features of a university hospital cohort. Neuroepidemiology 2002;21(3):153-158.

18. Ferraz AC, Gabbai AA, Abdala N, Nogueira RG. Magnetic resonance in HTLV-1 associated myelopathy: leukoencephalopathy and spinal cord atrophy. Arq Neuropsiquiatr 1997;55(4):728-736.

19. Shakudo M, Inoue Y, Tsutada T. HTLV 1 associated myelopathy: Acute progression and atypical MR findings. Am J Neuroradiol 1999;20:1417-1421.

20. Bagnato $\mathrm{F}$, Butman JA, Mora CA, et al. Conventional magnetic resonance imaging features in patients with tropical spastic paraparesis. J Neurovirol 2005;11(6):525-534.

Accepted 12 September 2012 